\title{
The Market for Ideas and Its Test Benches: (Scientific) Pertinence, (Economic) Profit, and (Political) Permission
}

\author{
${ }^{1}$ Octavian-Dragomir Jora, ${ }^{2}$ Matei-Alexandru Apăvăloaei, ${ }^{3}$ Mihaela lacob \\ ${ }^{1}$ The Bucharest University of Economic Studies, ${ }^{2}$ the Bucharest University of Economic Studies, ${ }^{3}$ the Bucharest \\ University of Economic Studies
}

\begin{abstract}
"The market for ideas" is placed by scholars and commoners alike between literary metaphors and catchy paraphrases. However, both economics and political sciences have at least something to say about the concept of "market for ideas", undoubtedly in addition to the sciences of cognition and communication. The "marketplaces" of ideas are a mixture comprising figments of "bazaars" (governed by the law of demand and supply) and "agorae" (governed by the democratic rule of law or by the despotic rule of men). Far from being freefloating and scarcityfree objects, ideas are (serviceable) products (calculatedly) produced by (resourceful) producers, and thus subject to profit-seeking judgments, and open to economic scrutiny. Also, ideas are the offshoot of nominally overrated, but otherwise heavily amended, freedom of expression (tempered in the political arena by the power of either blunt and rough majorities or by that of active and organized minorities). Thus, it is legitimate to continuously question which are and ought to be the mechanisms for securing the quest for truth, since only true/right/correct ideas are ultimately useful, yet shortsighted profiteering and forced (or accomplice) obedience might suggest otherwise. Scientific truth (i.e., in social sciences) is caught amongst epistemic as well as (pseudo-)economic and (poor) political filters. The purpose of this paper is the identification and investigation of the frameworks for the evaluation and explanation of the spread of scientific ideas, at the crossroads of the "true -false", "profitableunprofitable", "permitted-prohibited" filters. The perspective is both conceptual (theoretical) and contextual (historical), while the undertaken inquiry, although inevitably interdisciplinary, ultimately relies on economics, acting both as analytical groundwork and expressive case study.
\end{abstract}

Keywords: constraints; incentives; institutions; science; truth-seeking 